\title{
DUKUNGAN SUAMI DENGAN KEJADIAN DEPRESI PASCA MELAHIRKAN
}

\author{
Cindritsya Tolongan \\ Grace E.C Korompis \\ Minar Hutauruk \\ Program Studi Ilmu Keperawatan Fakultas Kedokteran \\ Univeristas Sam Ratulangi \\ Email : CindritsyaTolongan29@gmail.com.
}

\begin{abstract}
Abstrack : Postpartum is a mother after childbirth will experience some psychological, physical or hormonal changes that can cause the mother to experience stress which can continue to depression, so that postpartum depression can have a negative impact on the baby and mother. The purpose of this study was to determine whether there was a relationship between husband's support and the incidence of postpartum depression at the Tuminting Health Center. This research method uses a cross sectional design. The sampling technique used purposive sampling technique with a total sample of 50 respondents. Methods of data collection using a husband's support questionnaire and postpartum depression in the immunization room and maternal maternity to find out about husband's support and depression after giving birth and statistical tests using the chi square test. The results of the study obtained a p-value of $0.004(\leq \alpha=0.05)$ which means that there is a significant difference. The conclusion of the results of this study shows that there is a relationship that occurs in mothers after childbirth if there is no good husband support.
\end{abstract}

Keywords: Husband support wit the incidence of postpartum depression

\begin{abstract}
Abstrak : Pasca melahirkan merupakan ibu yang setelah melahirkan akan mengalami beberapa perubahan psikologi, fisik ataupun hormonal yang menyebabkan ibu dapat mengalami stres yang dapat berlanjut hingga depresi, sehingga depresi pasca melahirkan dapat berdampak buruk bagi bayi maupun ibu. Tujuan Penelitian ini adalah untuk mengetahui adakah hubungan dukungan suami dengan kejadian depresi pasca melahirkan di Puskesmas Tuminting. Metode penelitian ini menggunakan desain cross sectional. Teknik pengambilan sampel menggunakan teknik purposive sampling dengan jumlah sampel sebanyak 50 responden. metode pengumpulan data menggunakan kuesioner dukungan suami dan depresi pasca melahirkan di ruangan imunisasi dan bersalin ibu untuk mengetahui dukungan suami dan depresi setelah melahirkan dan uji statistic menggunakan uji chi square. Hasil penelitian di dapat nilai $p$-value sebesar $0,004(\leq \alpha=0,05)$ yang berarti ada perbedaan yang signifikan. Kesimpulan hasil penelitian ini menunjukan bahwa ada hubungan yang terjadi pada ibu setelah melahirkan jika tidak ada dukungan suami yang baik.
\end{abstract}

Kata kunci : Dukungan Suami Dengan Kejadian Depresi Pasca Melahirkan

\section{PENDAHULUAN}

Pasca melahirkan merupakan masa pulih Kembali setelah persalinan, yang dimulai dari persalinan selesai sampai alatalat kandungan kembali seperti sebelum melahirkan (Risa \& Rika, 2014). Pasca melahirkan merupakan fase transisi, yang dapat menyebabkan beberapa ibu mengalami krisis kehidupan, dimana setelah melahirkan ibu akan mengalami beberapa perubahan fisik dan psikologi. Perubahan fisik antara lain ialah, perubahan organ-organ reproduksi dan perubahan tubuh lainya seperti pinggul membesar, flek hitam dibagian perut (Stretc mark), payudara membengkak, kaki bengkak, Varises, kenaikan berat badan. 
Sehingga upaya perawat maupun keluarga sangat diperlukan, untuk kemampuan ibu beradaptasi dalam perubahan fisik saat pasca melahirkan (Anggraini, 2010). Dan juga perubahan psikologi antara lain kecemasan meningkat, perasaan murung, ingin menyakiti diri sendiri dan bayi, tidak mampu merawat bayi, tidak mampu menyusui dan juga stress (Fadlan, 2006). Beberapa ibu yang tidak mampu menyesuaikan perubahan psikologi dapat mengalami stress yang signifikan dan berkembang menjadi baby blues.

Baby blues merupakan perasaan sedih atau perasaan kacau, yg terdapat pada ibu post partum dan juga sindrom gangguan ringan yang terjadi pada beberapa ibu yang dialami pada hari pertama setelah melahirkan dan memuncak pada hari ketiga sampai hari kelima pasca persalinan (Alian, 2012), sehingga baby blues dapat berkembang menjadi depresi pasca melahirkan jika tidak ditangani dalam memasuki rentang waktu 14 hari. Buku panduan Obstetri Ginekologi menjelaskan lebih dari 20\%, wanita yang mengalami baby blues atau postpartum blues, yang dapat berkembang menjadi depresi pasca melahirkan.

Depresi pasca melahirkan dapat berdampak negatif pada ibu, anak, dan keluarga. Ibu yang mengalami depresi pasca melahirkan, minat dan ketertarikan terhadap bayinya berkurang, tidak mampu mengenali kebutuhan bayi, menolak untuk menyusui bayi dan ingin menyakiti diri sendiri ( berpikir untuk bunuh diri), bahkan bisa menyakiti bayinya sendiri. Depresi merupakan suatu penyakit yang menyebabkan gangguan perasaan, dan emosi yang dimiliki oleh individu yang ditunjuk sebagai suasana perasaan, yang menyatakan sekitar 10\%-15\% ibu pasca melahirkan mengalami depresi pasca melahirkan (Endang, 2015). Menurut Namora, (2009). Depresi pasca melahirkan juga merupakan kondisi serius yang mempengaruhi $8-20$ wanita setelah melahirkan, salah satu masalah umum yang terjadi pada 13\% wanita diseluruh dunia terlebih dinegara berkembang, namun beberapa wanita yang tidak menyadari bahwa mereka sedang mengalami kondisi seperti ini yang bisa membahayakan ibu dan perkembangan anaknya.

Angka kejadian depresi pasca melahirkan, menurut laporan World Health Organization (WHO) diperkirakan wanita yang melahirkan dan mengalami depresi ringan, berkisar 10 per 1000 kelahiran hidup dan depresi pasca melahirkan sedang atau berat berkisar 30 sampai 20 per 1000 kelahiran hidup (Soep, 2009). Di Asia dengan angka kejadian depresi pasca melahirkan cukup bervariasi, antara 2685\% (Iskandar, 2007 dalam Munawaroh, 2008). Di Indonesia beberapa penelitian sudah dilakukan, terhadap kasus depresi pasca melahirkan dengan angka kejadian bervariasi.

Penelitian Kasdus, (2013) di Rumah Sakit Umum Sigli sebanyak 6 ibu $(40 \%)$ setelah melahirkan hampir mengalami perasaan sedih atau sering disebut postpartum blues yang dapat berlanjut hingga depresi pasca melahirkan. Penelitian yang dilakukan oleh Asmayanti, (2017) di RSUD Senopati Bantul Yogyakarta, mencapai 26,9\% ibu mengalami depresi sedang, dan Penelitian yang dilakukan oleh Imaninditya, (2014) dipuskesmas klaten selatan kejadian depresi pasca melahirkanmencapai 33,3\% dan Penelitian yang dilakukan oleh Martini \& Septi, (2013) di Puskesmas Rumbia lampung tengah, kejadian depresi pasca melahirkan mencapai $53,2 \%$. Selain itu penelitian oleh Martini dan Septi, (2013) dan di Puskesmas Rumbia Lampung Tengah, (2013) menyimpulkan bahwa depresi banyak dialami pada ibu dengan latar pendidikan rendah dan usia ibu yang terlalu mudah beresiko tinggi.

Faktor - faktor yang berperan pada kejadian depresi pasca melahirkan antara lain ialah faktor hormonal, faktor umur dan paritas, pengalaman dalam proses persalinan, dan pelayanan kesehatan kurang baik, dukungan sosial dan 
dukungan suami. Dukungan suami merupakan salah satu faktor yang mempengaruhi terjadinya depresi, suami yang tidak memberikan perhatian, komunikasi, dan emosional yang intim membuat ibu rentang mengalami depresi.

\section{METODE PENELITIAN}

Penelitian ini termasuk dalam jenis penelitian kuantitatif dengan menggunakan metode penelitian analitik untuk menganalisis dukungan suami dengan kejadian depresi pasca melahirkan, Penelitian ini menggunakan desain penelitian cross sectional. Penelitian ini dilaksanakan di puskesmas Tuminting di Manado pada bulan Mei 2019 selama 3 minggu.

Populasi penelitian ini merupakan ibu pasca melahirkan sebanyak 65 ibu. Pengambilan sampel menggunakan teknik purposive sampling dengan rumus slovin maka didapatkan jumlah sampel 50 responden. Instrument penelitian yang digunakan untuk variabel dukungan suami dan depresi pasca melahirkan menggunakan kuesioner yang pernah digunakan sebelumnya oleh Asmayanti, (2017) di sekolah tinggi ilmu keperawatan Jenderal Achmad Yani Yogyakarta dan di anggap baik dan layak digunakan, kuesioner dukungan dan depresi oasca melahirkan terdiri dari 23 pertanyaan dukungan suami dengan pemberian bobot: apabila menjawab Tidak perna: skor 1 , Jarang: skor 2, kadang - kadang: skor 3, sering: skor 4, selalu: skor 5 dan instrument penelitian yang digunakan untuk mengukur variable depresi pasca melahirkan menggunakan kuesioner.

Kuesioner ini berjumlah 10 pertanyaan dengan pemberian bobot: Ya, sepanjang waktu : skor 4, Ya hampir sepanjang waktu : skor 3, Tidak terlalu sering: skor 2, Tidak sama sekali: skor 1. Setelah lembar kuesioner di isi oleh responden, peneliti mengumpulkan kembali lembar kuesioner. Pengolahan data yang diperoleh dari hasil penelitian ini dianalisis menggunakan uji statistik melalui sistem komputerisasi dengan beberapa tahap yaitu editing, coding, tabulasi data.

Analisa bivariat dalam penelitian ini yaitu untuk mengetahui hubungan dukungan suami dengan kejadian depresi pasca melahirkan pada ibu pasca melahirkan diPuskesmas Tuminitng. Peneliti menggunakan uji Chi-square dengan tingkat kemaknaan $95 \%(\alpha=$ $0,05)$.

\section{HASIL dan PEMBAHASAN \\ 1. Karakteristik Responden}

Tabel 1. Distribusi Responden berdasarkan umur.

\begin{tabular}{ccc}
\hline Umur & n & \% \\
\hline 20-25 Tahun & 41 & 82,0 \\
26-30 Tahun & 6 & 12,0 \\
31-35 Tahun & 2 & 4,0 \\
>35 Tahun & 1 & 2,0 \\
\hline Total & $\mathbf{5 0}$ & $\mathbf{1 0 0}$ \\
\hline
\end{tabular}

Sumber : Data Primer 2019

Berdasarkan tebel diatas menjelaskan bahwa dari 50 responden didapati sebagian besar responden berumur 20 - 25 sebanyak 41 responden (82\%). Hasil yang peneliti lakukan pada responden lebih banyak didapati yang berusaia 20 - 25 tahun, dikarenakan pada usia seperti ini masa peralihan seseorang menjadi lebih dewasa dari masa remaja akhir.

Ibu yang harus menyesuaikan untuk menjadi seorang ibu setelah melahirkan ibu harus menyiapkan diri dan mental untuk bisa mengetahui mengurus bayi agar ibu dapat terhindar dari depresi pasca melahirkan yang di dengar dari penyuluhan yang peneliti lakukan dan dapat ditangani dengan baik karna mendapatkan dukungan yang baik dari suami bahkan keluarga dan lingkungan sehingga dapat terhindar dari kejadian depresi setelah melahirkan. Sebaliknya jika ibu pada usia seperti ini jika ibu tidak bisa menyesuaikan diri dapat mengalami gejala-gejala depresi pasca melahirkan 
karna banyaknya tekanan dan kurangnya dukungan dari suami.

Usia sangat mempengaruhi ibu terkena depresi setelah melahirkan. Hal ini sebagaimana dikemukakan oleh Suryani (2008), mengatakan bahwa mereka yang berusia lanjut biasanya mudah terkena depresi.

Tabel 2. Karakteristik responden berdasarkan pekerjaan.

\begin{tabular}{lcc}
\hline Pekerjaan & n & \% \\
\hline Honorer & 1 & 2,0 \\
IRT & 43 & 86,0 \\
Perawat & 2 & 4,0 \\
Swasta & 4 & 8,0 \\
\hline Total & $\mathbf{5 0}$ & $\mathbf{1 0 0}$ \\
\hline
\end{tabular}

Sumber: Data Primer 2019.

Karaketristik pekerjaan dari tabel 2 diatas menjelaskan bahwa dari 50 responden didapati sebagian besar responden berpekerjaan IRT sebanyak 43 responden $(88 \%)$.

Perkerjaan sebagai IRT sangatlah mempengaruhi kondisi ibu dimana ibu harus memikirkan pekerjaan rumah dengan keadaan ibu yang mungkin merasa sakit akan tetapi masih terbeban dengan perannya sebagai IRT dan mengurus semua pekerjaan rumah tanpa dukungan suami, suami yang tidak membantu dalam mengurus atau membersihkan rumah dan membiarkan ibu mengurusnya dan membuat kondisi ibu tidak baik sehingga ibu dapat mengalami gejala depresi pasca melahirkan. (Bobak dkk, 2005).

Tabel 3. Karakteristik responden berdasarkan pendidikan terakhir.

\begin{tabular}{lll}
\hline Pendidikan terakhir & $\mathbf{n}$ & $\mathbf{\%}$ \\
\hline SD & 3 & 6,0 \\
SMP & 2 & 4,0 \\
SMK & 37 & 74,0 \\
D3 & 1 & 2,0 \\
D4 & 1 & 2,0 \\
S1 & 6 & 12,0 \\
\hline Total & $\mathbf{5 0}$ & $\mathbf{1 0 0}$ \\
\hline Sumber: Data Primer & $\mathbf{2 0 1 9}$ &
\end{tabular}

Sumber: Data Primer 2019.
Pendidikan terakhir di atas menjelaskan bahwa dari 50 responden didapati sebagian besar responden berpendidikan SMA/SMK sebanyak 37 responden (74\%). Hasil wawancara dan menggunakan kuesioner yang peneliti lakukan dengan ibu pasca melahirkan maupun ibu yang membawa anak imunisasi, berpendidikan SMA/SMK, karena pada pendidikan seperti ini ibu tidak mempelajari atau mengetahui secara dewasa tentang pasca melahirkan sehingga beberapa hal yang akan terjadi pada ibu setelah melahirkan ibu hanya membiarkan dan tidak menanganinya, oleh sebab itu sebagian besar ibu mengatakan kurang pengetahuan tentang depresi setelah melahirkan sehingga ibu yang mengalami gejala depresi tersebut tidak menangangi gejala tersebut dan hanya membiarkan gejala tersebut hilang dengan sendirinya.

Depresi pasca melahiran kurang terjadi pada ibu yang sudah mengetahui gejala depresi atau ibu yang memiliki tingkat pendidikan yang cukup tinggi.

Tabel 4. Distribusi Responden Berdasarkan Status Partus.

\begin{tabular}{lcl}
\hline Status Paritas & $\mathbf{n}$ & $\mathbf{\%}$ \\
\hline P1 & 16 & 32,0 \\
P2 & 26 & 52,0 \\
P3 & 8 & 16,0 \\
\hline Total & $\mathbf{5 0}$ & $\mathbf{1 0 0}$ \\
\hline
\end{tabular}

Sumber: Data Primer 2019.

Status paritas berdasarkan tabel 4 menjelaskan bahwa dari 50 responden didapati sebagian besar responden dengan status partus $\mathrm{P} 2$ berjumlah 26 responden (52\%). Dapat dilihat dari hasil yang didapatkan ibu yang dapat mengalami depresi pasca melahirkan ibu yang baru pertama kali melahirkan.

Ibu yang baru pertama kali melahirkan sulit untuk menyesuaikan dirinya dalam mengurus sang bayi, dikarenakan ibu yang baru pertama kali melahirkan belum bisa terlalu memahami keadaan bayi ataupun ibu yang baru pertama kali melahirkan gampang 
terpengaruh dengan keadaanya sehingga ibu yang baru pertama melahirkan rentang mengalami depresi karena tidak dapat menyesuaikan diri terhadap kondisinya saat itu. Faktor selama proses kehamilan dan persalinan sangat mempengaruhi ibu mengalami depresi pasca melahirkan

\section{Analisa Univariat}

Tabel 5. Distribusi Responden Berdasarkan dukungan suami.

\begin{tabular}{lcc}
\hline Dukungan suami & $\mathbf{n}$ & $\mathbf{\%}$ \\
\hline Baik & 30 & 60,0 \\
Kurang Baik & 20 & 40,0 \\
\hline Total & $\mathbf{5 0}$ & $\mathbf{1 0 0}$ \\
\hline
\end{tabular}

Sumber: Data Primer 2019.

Berdasarkan tabel di atas menjelaskan bahwa dari 50 responden didapati sebagian responden dengan dukungan suami baik berjumlah 30 responden $(60 \%)$ dan dukungan kurang baik 20 responden $(40 \%)$. hasil ini menunjukan bahwa dukungan suami pada ibu pasca melahirkan yang ada disekitaran wilayah puskesmas tuminting dengan dukungan suami baik sebanyak 30 orang suami yang memperhatikan istri setelah melahirkan, memberikan perawatan setelah melahirkan dengan baik, selalu memberikan perhatiaan lebih kepada sang istri dan bersikap baik, selalu ada saat ibu setelah melahirkan dan memotivasi ibu untuk tetap menjadi seorang ibu yang baik kepada sang buah hati.

Dukungan suami kurang baik sebanyak 20 orang yang diberikan pada ibu, suami tidak memberikan perhatian yang khusus, suami yang membiarkan ibu melakukan pekerjaan dan mengurus bayi sendiri, suami tidak memberikan motivasi dan dukungan yang lebih sehingga membuat ibu tidak yakin dalam mengurus bayi atau menjadi peran seorang ibu. Hasil penelitian ini sama dengan hasil yang di dapatkan oleh Asmayanti, (2010) didapatkan hasil menunjukan bahwa dukungan suami atau karakter individu yang berhubungan kejadian depresi pospartum adalah dukungan sebanyak $(59,7 \%)$ suami mendukung ibu setelah melahirkan.

Tabel 6. Distribusi Responden Depresi PascaMelahirkan.

\begin{tabular}{lcc}
\hline $\begin{array}{l}\text { Depresi Pasca } \\
\text { Melahirkan }\end{array}$ & n & \% \\
\hline Depresi & 17 & 34,0 \\
Tidak Depresi & 33 & 66,0 \\
& & \\
\hline Total & $\mathbf{5 0}$ & $\mathbf{1 0 0}$ \\
\hline Sumber: Data Primer 2019. &
\end{tabular}

Berdasarkan tabel di atas menjelaskan bahwa dari 50 responden didapati sebagian responden yang mengalami depresi sebanyak 17 orang $34 \%$ responden dan yang tidak mengalami depresi sebanyak 33 orang $66 \%$ responden. dari hasil penelitian yang saya dapatkan dikarenakan ibu dapat menyesuaikan diri setelah melahirkan, ibu dapat memahami keadannya setelah melahirkan dan tidak membiarkan berada pada keadaan yang tidak baik, sering berbagi cerita bersama dengan orang lain dan juga pada suaminya sendiri.

Ibu yang mengalami depresi sebanyak 20 responden karna keadan tekanan masalah yang membuat ibu tidak mampu, ibu sering berpikir bahwa tidak bisa mengurus bayi dan ibu sering berpikir untuk menyakiti dirinya sendiri karena beberapa faktor atau faktor dukungan suami yang tidak diberikan setelah melahirkan atau masalah setelah melahirkan sehingga ibu bisa mengalami depresi stelah melahirkan, depresi pasca melahirkan terletak pada frekuensi, intesitas dan durasi gejala (Glade, 2000).

Depresi pasca melahirkan dapat terjadi dari 2 minggu sampai 1 tahun setelah melahirkan. Ibu mungkin merasa marah bingung, panik dan tidak berdaya (Glade, 2000). Hasil penelitian ini sesuai dengan Asmayanti, (2017) yang menunjukan ibu nifas tidak banyak yang mengalami depresi pasca melahirkan 


\section{Analisa Bivariat}

Tabel 7. Hubungan dukungan suami dengan keadian depresi pasca melahirkan.

\begin{tabular}{|c|c|c|c|c|}
\hline \multirow[t]{2}{*}{ Depresi } & \multicolumn{2}{|c|}{ Dukungan Suami } & & \multirow[t]{2}{*}{$\begin{array}{c}\rho \\
\text { Value }\end{array}$} \\
\hline & $\begin{array}{c}\text { Baik } \\
\text { n }\end{array}$ & $\underset{n}{\text { Kurang baik }}$ & Total & \\
\hline \multirow{2}{*}{$\begin{array}{l}\text { Ya } \\
\text { Tidak }\end{array}$} & 5 & 12 & 17 & \multirow{3}{*}{0,04} \\
\hline & 25 & 8 & 33 & \\
\hline Total & 3 & 29 & 50 & \\
\hline
\end{tabular}

Sumber: Data Primer 2019.

Berdasarkan penelitian yang didapatkan menunjukan dari 50 responden dengan kejadian depresi pasca melahirkan, terdapat 17 responden yang mengalami depresi pasca melahirkan dengan dukungan suami baik sebanyak 5 responden dan dukungan suami kurang baik sebanyak 12 responden. Kemudian untuk ibu yang tidak mengalami depresi sebanyak 33 respnden dengan dukungan suami baik sebanyak 25 responden dan dukungan suami kurang baik sebanyak 8 responden. Hasil uji Chi - Square dengan tingkat kepercayaan 95\% $(\alpha>0,05)$, menunjukan adanya hubungan dukungan suami dengan kejadian depresi pasca melahirkan di Puskesmas Tuminting. Dimana nilai $\mathrm{p}=0,04$ lebih kecil dari nilai $\alpha=0,05$.

Hasil penelitian responden yang mengalami depresi pasca melahirkan sebanyak 17 responden tapi mendapatkan dukungan suami baik sebanyak 5 responden dikarenakan ibu tersebut tidak siap pada kehamilannya, terdapat masalah yang tidak diceritakan kepada suaminya meskipun ibu tersebut mendapatkan dukungan suami baik setelah melahirkan, akan tetapi ibu tersebut sering merasa tidak bahagia karna masalah saat pernikahan, sering menyalakan diri - sendiri jika mendapatkan masalah dilingkungan sekitar, memendam sendiri masalah yang datang dan tidak berbagi cerita kepada suaminya, merasa khawatir tanpa alasan yang jelas.
Penelitian ini menunjukan Ibu yang mengalami depresi dikarenakan ibu tersebut tidak bisa memahami keadaan setelah melahirkan, tidak bisa menerima perubahan fisik atau psikologi, ibu dengan usia sangat muda dan merasa tidak bisa mengurus bayi, meskipun dukungan suami yang baik yang diberikan suami. bahwa dukungan suami merupakan dorongan, motivasi terhadap istri, baik secara moral maupun material. Depresi pada ibu pasca melahirkan disebabkan karena adanya hormon endorphine adalah senyawa morphine alami yang dihasilkan tubuh yang mengalami efek rasa senang (euphoria). Jika sadar hormon endorphine mengalami penuruanan, maka ibu akan mengalami depresi atau dysphoria atau kesedihan Bobak (2005).

Ibu yang tidak mengalami depresi pasca melahirkan sebanyak 33 responden dan mendapatkan dukungan suami baik sebanyak 25 responden dilihat dari hasil penelitian meskipun ada hubungan dukungan dengan kejadian depresi pasca melahirkan akan tetapi yang paling banyak ibu tidak mengalami depresi dan mendapatkan dukungan suami baik terlihat saat penelitian, suami yang menemani ibu saat membawa anak imunisasi dan dilihat dari hasil kuesioner ibu tidak mengalami depresi dikarenakan ibu dapat mengatasi keadaan setelah melahirkan, ibu selalu menceritakan hal-hal yang membuat dia terbeban, ibu sering meminta bantuan kepada orang sekitar terlebih suami, ibu tidak membiarkan keadaan buruk menimpanya, ibu sering mendapatkan perhatian yang lebih dari orang-orang sekitar dan suami.

tidak mengalami depresi $\begin{gathered}\text { Berdasarkan penelitian Ibu yang } \\ \text { metapi }\end{gathered}$ mendapatkan dukungan suami kurang sebanyak 8 responden dilihat dari hasil penelitian suami masih berusia muda atau suami istri yang sudah berstatus cerai, suami yang meninggalkan istri (cerai) dan suami yang meninggalkan istri karna meninggal dunia, ibu sangat berperan yang terbaik menjadi orang tua, ibu harus bisa 
memahami keadaanya dan bayinya jadi meskipun suami tidak memberikan dukungan suami yang tidak baik atau suami meninggalkan saat anak sudah lahir ibu tersebut melakukan hal-hal yang lebih postif, seperti sering refresing keluar rumah bersama bayinya, lebih memperbanyak kegiatan bekerja dan selalu menguatkan hati agar supaya bisa terhindar dari depresi tersebut.

Depresi post partum banyak perempuan tidak mau bercerita bahwa mereka sedang mengalami depresi postpartum, karena merasa malu, takut dan merasa bersalah karena merasa depresi disaat seharusnya mereka harus merasa bahagia dan takut dikatakan tidak layak menjadi ibu. Faktor faktor lain seperti ibu yang merangkap menjadi ayah bekerja diluar selain menjadi IRT, ibu yang mempunya tingkat pendidikan yang lebih tinggi seperti S1 dll, ibu yang sudah melahirkan beberapa kali sehingga sudah mendapatkan pengalaman, dan menjadikan motivasi jika hidup sendiri akan lebih baik jika semua yang dilakukan dengan perasaan yang tenang tidak kacau dan tidak emosi sehingga terhindar dari depresi meskipun dukungan suami tidak baik.

Hasil penelitian ini sama dengan penelitian Irwati dan Farida, (2013) dengan hasil menunjukan ada pengaruh kelompok umur, parita, pendidikan, dukungan suami, status kehamilan dan pengetahuan terhadap terjadinya postpartum blues. Faktor paritas post partum banyak terjadi pada ibu primipara mengingat ibu yang baru pertama kali melahirkan dan memasuki perannya sebagai seorang ibu, tetapi tidak menuntut kemungkinan juga terjadi pada ibu multipara jika ibu mempunyai riwayat postpartum blues sebelumnya.

Penelitian ini semua responden memiliki paritas primipara sebanyak 16 orang dan multipara sebanyak 26 orang. Hasil penelitian yang dilakukan (Asmayanti, 2017) terdapat keeratan hubungan yang bermakna antara dukungan suami dengan kejadian depresi post partum. Menurut (Lubis 2010) ibu post partum mungkin perlu untuk mengatur atau menata kembali kegitan yang rutin selalu dilakukan atau mungkin menghilangkan beberapa kegiatan yang berat dan perawatan bayi dapat dilakukan oleh petugas kesehatan. Berdasarkan hasil penelitian dan teori pendukung peneliti beranggapan bahwa kejadian depresi setelah melahirkan yang terjadi pada ibu dikarenakan banyaknya faktor terutama dukungan suami jika suami memberikan dukungan tidak baik setelah melahirkan dan dengan ibu yang mempunyai kehamilan yang tidak direncanakan dengan pendidikan yang sangat rendah dan status ekonomi yang menipis membuat ibu mengalami stress yang bisa berakibat hingga terkena depresi yang tidak bisa ditangani dan akan berdampak buruk bagi anak, ibu maupun suami.

\section{SIMPULAN}

Hasil penelitian menunjukan adanya hubungan antara dukungan suami dengan kejadian depresi pasca melahirkan di Puskesmas Tuminting Manado sebagian besar ibu pasca melahirkan di puskesmas Tuminting Manado mendapatkan dukungan suami baik dan ada beberapa ibu mendapatkan dukungan suami kurang baik sebagian besar ibu pasca melahirkan dipuskesmas Tuminting Manado yang mengalami depresi pasca melahirkan dikarenakan bebarapa karaketristik terutama dukungan suami akan tetapi palinga banyak ibu tidak mengalami depresi pasca melahirka.

\section{DAFTAR PUSTAKA}

Asmayanti, (2017). Hubungan Dukungan Suami Dengan Kejadian Depresi Postpartum di RSUD Panembanan Senopati Bantul Yogyakarta, http://repository.unjaya.ac.id/2119/2/ ASMAYANTI_2213059_pisah pdf. Diakses pada tanggal 10 Oktober 2018. 
e-journal Keperawatan (e-Kp) Volume 7 Nomor 2, Agustus 2019

Anggraini Y (2010) ,.. Asuhan Kebidanan Masa Nifas, Yogyakarta: Pustaka Rihama.

Kasdus, A, N. Staf Pengajar Studi Prodi DIII KEBIDANAN Unisulla Semarang, Mencegah Depresi Pasca Melahirkan, http://research.unissula.ac.id/file/pub likasi/210104090/9942Postpartum_B lues.pdf. Diakses pada tanggal 10 Oktober 2018.

Ayu, F, Fatmah, L. (2008). Dukungan suami dan Depresi Pasca Melahirkan. fpsi.mercubuanayogya.ac.id/wp-content/.../jurnalnoor-2008_depreso. Diakses pada tanggal 10 Oktober 2018

Bobak, Laurdermik, Jensen. (2005). Buku Ajar Keperawatan Maternitas. Jakarta : EGC.

Elvira, Silvya.,. D. (2006). Depresi pasca Persalinan. Jakarta: FK UI https://books.google.co.id/books?id= ephaDwAAQBAJ\&pg=PA35\&dq=d epresi+pasca+persalinan+elvira\&hl= id\&sa $=$ X\&ved $=0$ ahUKEwilyqXwerfAhWMbysKHZE3BSMQ6AEILj $\mathrm{AB} \# \mathrm{v}=$ onepage $\& \mathrm{q}=$ depresi\%20pasc a.

Fadlan, F, M . (2010). Buku Ajar Keperawatan Keluarga: Riset, Teori dan Praktik Jakarta EGC.

Glade, B. Curtis, (2000). Kehamilan di Atas Usia 30.

Imaninditya,Y, \& Murwati. (2013). Studi Deskriptif tingkat depresi postpapartum pada ibu nifas diwilayah kerja puskesmas klaten selatan

https://d3bidanpoltekkessolo.files.wo rdpress.com/2014/11/tingkat-depresipostpartum-pada-ibu-nifas-

convert.pdf. Diakses pada 3 Oktober 2018
Munawaroh, H. (2008). Hubungan Paritas Dengan Kemampuan Mekanisme Koping Dalam Menghadapi Postpartum Blues RSUD Dr. Moewardi Surakarta, http://eprints.ums.ac.id/885/1/J21004 0018.pdf. Diakses pada tanggal 10 Oktober 2018.

Zulpatin, N, Arief, W, Endang. W (2017). Faktor Determinan Depresi Postpartum di Kabupaten Lombok Timur http://ejournal.litbang.depkes.go.id/i ndex.php/hsr/article/download/6137/ 5611. Diakses pada tangga 11 Februari 2019

Martini, S \& Septi, W, (2014) Hubungan Dukungan Suami dengan Kejadian Depresi Post Partum pada Ibu Nifashttps://ejurnal.poltekkestjk.ac.id/index.php/JKM/article/view/26 0 Diakses pada tanggal 15 Maret 2019

Namora, L (2009). Depresi Tinjauan Psikologi

https://books.google.co.id/books?id= p_pDDwAAQBAJ\&pg=PR3\&dq=na mora $+2009 \& h l=i d \& s a=X \& v e d=0 a h$ UKEwiRtd2eprfAhXDuY8KHf21AcQQ6AEIPjAE \#v=onepage \&q=namora\%202009\&f $=$ false. Diakses pada tanggal 9 Oktober 2018

Risa, P dan Rika, A. (Ed 1, Cet,.1). (2014). Panduan Lengkap Asuhan Kebidanan Ibu Nifas Normal (Askeb III).

https://books.google.co.id/books?id= Fmz_CAAAQBAJ\&printsec $=$ frontco ver\&dq $=$ Panduan + Lengkap + Asuhan +Kebidanan+Ibu+Nifas+Normal+(A skeb+III).\&hl=id\&sa $=X \& v e d=0 a h U$ KEwiJmq3XqerfAhUIQY8KHbt3Ab MQ6AEIKTAA. Diakses pada tanggal 12 Oktober 2018

Soep, (2009). Pengaruh Intervensi Psikoedukasi Dalam Mengatasi Depresi postpartum di RSU dr Pirngandi Medan. 
e-journal Keperawatan (e-Kp) Volume 7 Nomor 2, Agustus 2019

http://repository.usu.ac.id/bitstream/h andle/123456789/6885/?sequence $=1$. Diakses pada tanggal 12 Januari 2019

Th. Endang.P \& Elisabeth, S, W. (2015). Ilmu OBSTETRI \& Ginekologi Sosial untuk Kebidanan.

Lubis, L.N. (2009). Depresi Tinjauan Psikologi, Edisi.2. EGC: Jakarta.

Yanita, A dan Zamralita. (2001). Persepsi terhadap Dukungan Suami pada Primipara Journal Unair journal.unair.ac.id/download fullpapers-jpkk20e91761002full.pdf. Diakses pada tanggal 14 Maret 2019

Prasetyo, T, D. (2015) Hubungan Antara Usia dengan kejadian Postpartum Blues di RSUD Panembahan Senopati Bantul Yogyakarta. Skripsi. Program Studi Ilmu Keperawatan Sekolah Tinggi Ilmu Kesehatan Jendreal Achmad Yani Yogyakarta. Diakses pada tanggal 15 Maret 2019. 